\title{
Piston ANd Ring Initial Design Evaluation
}

\author{
Walter Zottin, Marcio Yamawaki e Marcos Manoel Valverde Pereira \\ ${ }^{1}$ MAHLE Metal Leve S.A.
}

E-mails: walter.zottin,@br.mahle.com, marcio.yamawaki@br.mahle.com, marcos.pereira@br.mahle.com

\begin{abstract}
In the last years, the automotive industries have intensified the use of numerical simulation tools in their developments, reducing the time and costs of projects and optimizing the components performance. However, the use of such tools as a step of product design workflow is not a regular practice due to the extensive computational time and the advanced level of expertise required.

With the improvements of computational processing and the enhancement of simulation codes, the time necessary to run a simulation was reduced to minutes or even seconds. So, the most time-consuming activities are the input data processing and the evaluation of the simulation results.

Taking this in consideration, the PRIDE code (Piston and Ring Initial Design Evaluation) was developed considering a customized interface for preliminary ring dynamic simulation, supporting pistons and rings initial design proposals. The main advantage of this approach is a higher robustness on pistons and rings initial designs, reducing the loops and interactions until the final design version.

This paper presents the organization of the PRIDE code, illustrating results possible to be anticipated during design with this simulation.
\end{abstract}

\section{INTRODUCTION}

The continued increase in thermal and mechanical internal combustion engine loads as a result of higher power density and more restricted fuel economy requirements and emission rules demands improved power cell units (PCU) performance in order to guarantee the engine functionality such as gas sealing, oil control and durability.

On the other hand, due to the high competitiveness in the automotive market, the car manufacturers and the engine developers are concentrating as many efforts as possible in order to reduce the lead-time to production and to promote cost reduction of their engine developments, while improving quality and performance.

In this scenario, it is mandatory to develop piston and ring projects which could fully cope with the required engine performance as well as the customer project time schedule.

The use of simulation techniques has become an important tool in order to reduce the leadtime demanded for an engine and/or product development cycle. More and more, the engine tests are being replaced by numerical simulations, which generate cost-effective and earlier information to support the engineering decisions, reducing the number of engine tests. The 
components and engine manufacturers are investing greatly in simulation tools which may be used to assist the design of a single component or of an entire system [10].

Based on that, the piston ring numerical simulation tools are important instruments to support new piston and ring product developments, contributing to improve their performance, reduce costs and testing lead-time. With their help, comprehensive studies of the PCU are done to better understand the piston/rings movement, predict the engine behavior and performance in terms of blow-by and oil consumption tendencies [1,5].

Thus, in order to maximize the potential benefits of ring dynamic simulation, MAHLE has developed a practical and user friendly tool named PRIDE (Piston and Ring Initial Design Evaluation). Using such tool in the initial stage of piston and ring project designs enables anticipation of potential non desirable behavior of the involved components, even without precise information about the engine, which is usually the case during the design phase.

This tool has been globally implemented at MAHLE product design engineering departments as a routine analysis tool to improve the initial piston and ring designs. It has been defined as one of the major steps of the piston and ring design flow in order to reduce the product leadtime development cycle combined with the improvement of piston and ring performance.

\section{PISTON RING SIMULATION}

MAHLE is a member of the Massachusetts Institute of Technology (MIT) Consortium on Lubrication in IC engines. The main purpose of this Consortium is to develop knowledge and tools for the development of power cylinder system through modeling and experiments. One of these tools is a ring dynamic simulation code that has been used by MAHLE ring simulation teams worldwide for the last 15 years, accumulating a long list of case studies and an extensive database of engine running condition data.

The code uses an axisymmetric (2D) approach to simulate the ring dynamic behavior, considering mixed-lubrication in a steady-state engine running condition [1,2]. The main inputs are listed below:

- Basic engine parameters (i.e. displacement, stroke, rpm, etc);

- Engine running conditions (i.e. speed, cylinder pressure versus crankshaft angle, etc);

- Piston Finite Element Analysis (FEA) results (temperatures and deformations);

- Hot bore distortion;

- Piston geometry;

- Rings geometry and running faces profiles;

- Lubricant oil properties.

The software calculates the piston land pressures, gas flow and ring pack motion behavior, which are mandatory for blow-by estimation and the main outputs are listed below:

- Piston land gas pressures;

- Ring motion (lift + twist + collapse);

- Inter-ring mass flow; 
- Piston grooves and ring end gaps mass flow;

- Piston grooves oil transport;

- Ring gaps dynamic opening.

Analyzing the results of the simulation it is possible to predict the ring pack behavior regarding gas flow and ring motion and qualitatively lube oil consumption (LOC) tendencies.

In general, this kind of tool was commonly used for problem solving tasks, contributing to improve and/or correct non desirable ring pack behavior at an advanced stage of product development.

Additionally, the total number of input data is quite high and needs to be manually handed. Due to this fact, this kind of simulation usually requires a simulation expert, restricting its use as routine basis by Product Development Engineering. In this way, the use of simulation was so far restricted to some cases.

Thus, MAHLE clearly identified the need of modifying this scenario, putting more efforts in the predictive approach in order to improve the support of initial design phase. For that, two major actions were done. The first one was to revise its design flow, improving the robustness of the actions which directly create a better product development. The second action was the development of an automated tool (PRIDE) to be used by the product engineering teams for initial ring dynamic simulation.

\section{RING DESING FLOW}

The revised MAHLE standard about ring design flow describes the design process of a piston ring (figure 1). This standard assures the same quality level in all MAHLE ring design locations. In this improved ring design flow, there are two simulation requirements. The usual one is required during the step 5.3 (in figure 1) and is executed by the simulation team. It considers the entire MIT code modules and uses information from engine tests to verify the prototype, in order to check the ring pack performance and/or evaluate chances of optimization (higher performance, failure analysis among others).

The newly added second simulation requirement is during step 5.1 (in figure 1), so PRIDE is used in this phase to help piston ring designer to better define the ring and piston initial features, improving the definition of the prototypes. In this phase, it is possible to explore more closely the piston and rings different designs and predict the impact on ring performance, refining the initial design in order to reduce the validation test loops (steps 5.2 to 5.5 in the figure 1). In this way, PRIDE is a new tool supporting ring designer, in addition to its own knowledge and experience. 

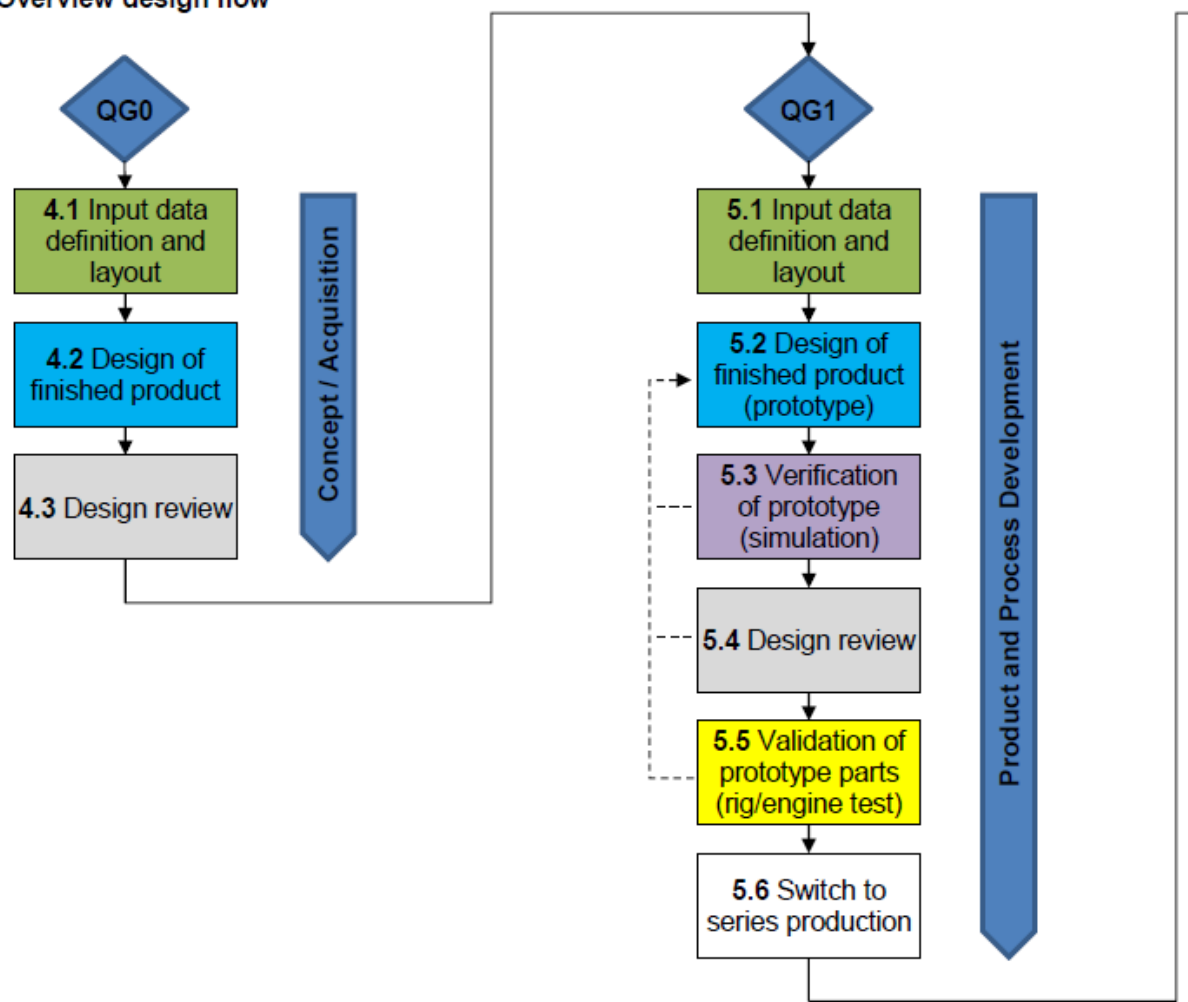

Figure 1 - Piston ring design flow detailed

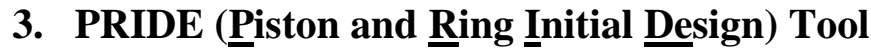

As mentioned before, the PRIDE tool is a customized interface for ring dynamic simulations, to be mainly used in routine analysis by product engineering departments, supporting piston and piston ring pack initial design proposals. It is applied during the layout definition and before prototype validation, so in most of the cases, it is used in a phase that only few information about the engine performance is known. Taking this in consideration, most of the input parameters are selected from a simulation database, consisting of data from validated cases.

The most important result expected from PRIDE is to support the better definition of piston land clearances, piston ring gap chamfers, piston ring end gaps, chamfers/steps for ring twist, axial clearances between piston groove and ring and piston groove back clearances on the initial design proposal. Figure 2 shows schematically the PRIDE concept. 


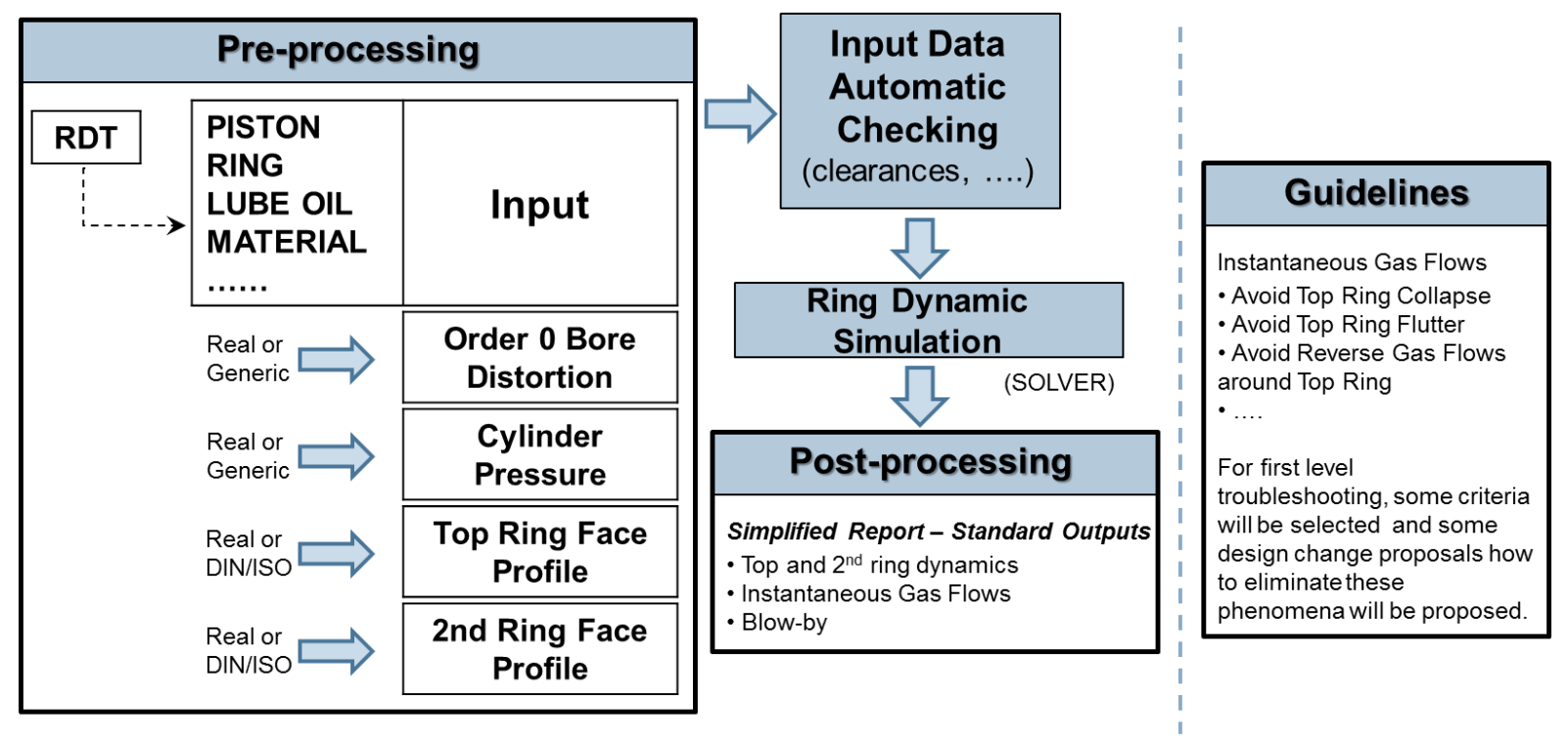

Figure 2 - PRIDE concept

An automatic input data transfer from piston and piston ring drawings as well as other calculations tools like piston finite element (FE) calculation was developed. The idea behind this concept is to minimize as much as possible the need of direct human input, making the simulation process as automatic as possible. Doing that, the lead time to prepare and complete a routine ring dynamics simulation is reduced at least by $40 \%$ compared to the conventional process.

To make this concept operational, 3 basic macros were developed, which are responsible for transferring data from other systems to PRIDE. The first macro transfers all the piston geometric data from the drawings and CAD system to PRIDE. In this step, the piston geometry is defined. The second macro is responsible for transferring all the ring pack geometry and the third macro for transferring the entire engine operating condition data, including the gas pressure traces, piston and liner temperature distributions and hot bore distortion.

Another extremely important step of the PRIDE concept is the automatic generation of the standard report, summarizing the relevant output results to the user, without the need of manual preparation. Figure 3 shows the top level windows of the PRIDE users interface 


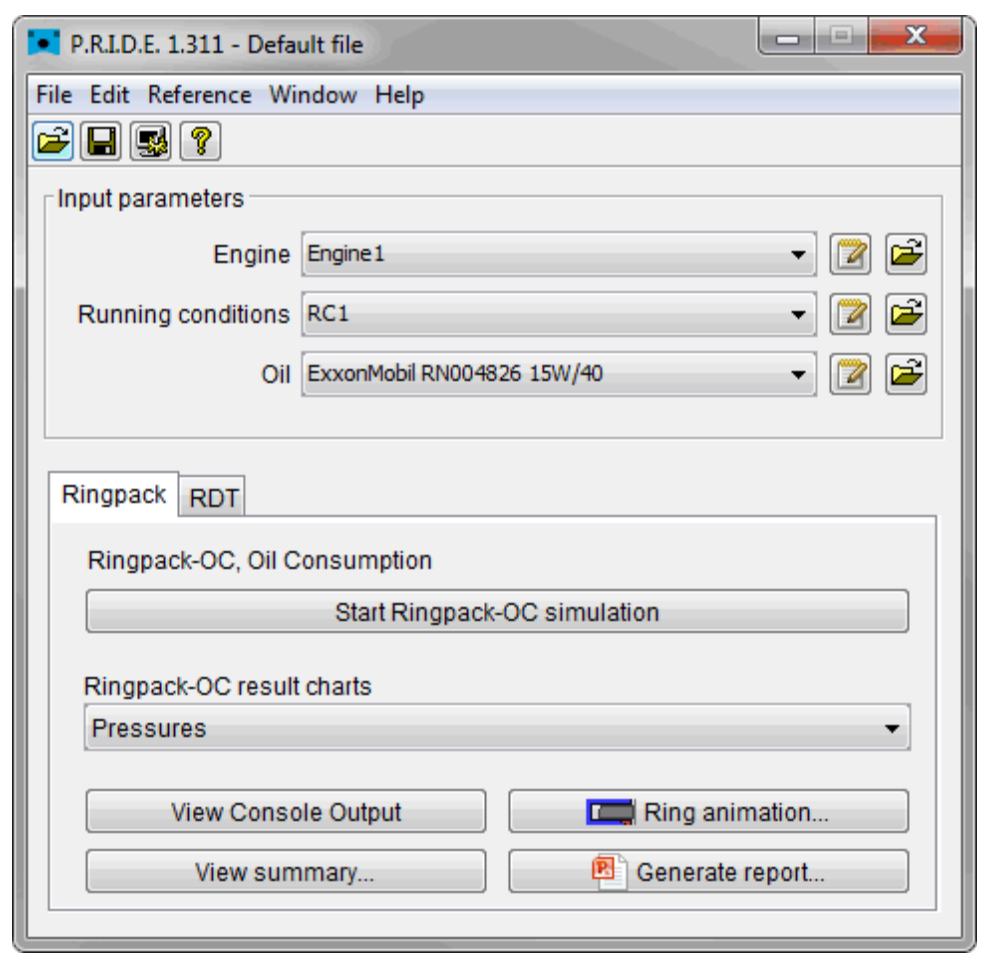

Figure 3 - PRIDE top level window

The PRIDE code and the revised piston ring design flow standard are already worldwide implemented in all MAHLE locations responsible for piston ring design projects.

\section{Case Study}

In order to exemplify the use of PRIDE code, two case studies considering the development of piston and piston rings were selected and are detailed below.

\subsection{Case Study 1 - SI engine}

This case study shows the application of PRIDE code for a SI engine. The purpose of this study was to analyze the ring pack dynamics in order to prevent any non-desirable ring behavior as well as to minimize as much as possible the engine blow-by through the optimization of the end gaps of top and second compression rings and the clearance between piston second land and cylinder [4,5,9].

Figure 4 shows the inter-ring gas pressure and rings axial lift results for the "pre-design" and the "initial proposal" versions. The "pre-design" was the starting point design, which was based on the MAHLE database and knowledge. The "initial proposal" was the design obtained after PRIDE calculation and it was the initial design offered to customer. 

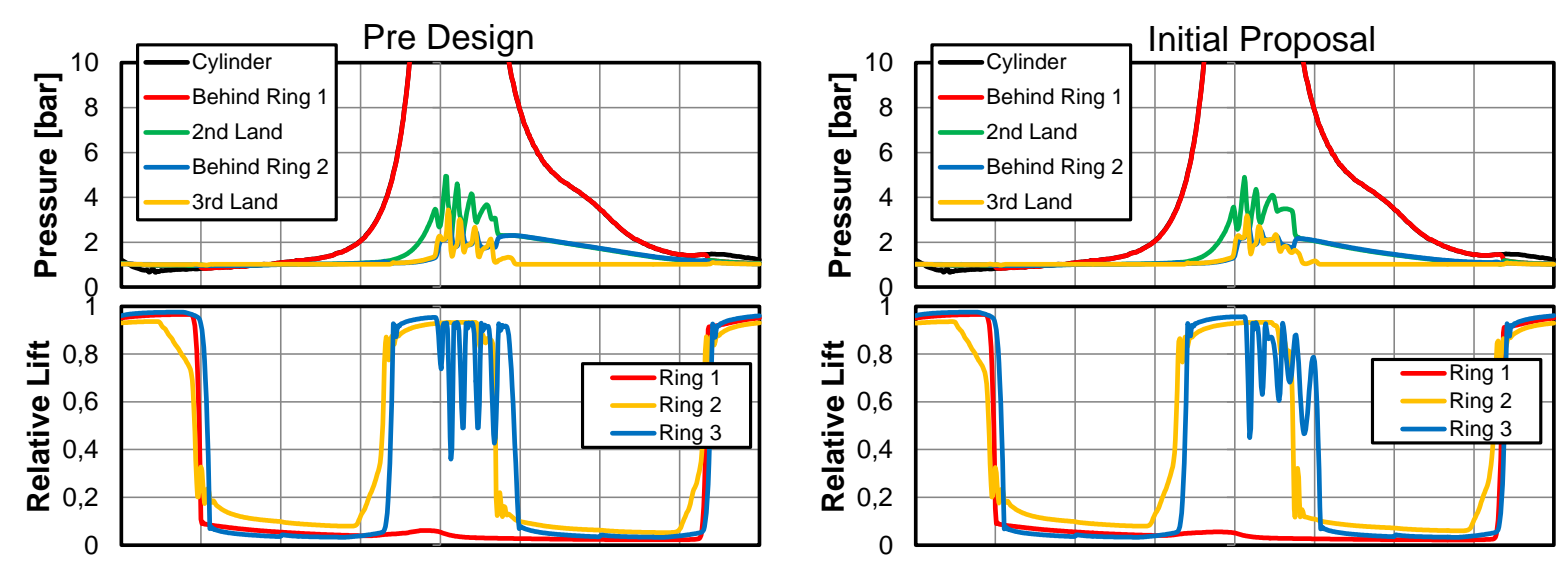

Figure 4 - Inter-ring gas pressures and rings axial lifts (case study 1)

The results do not show any abnormal ring pack behavior for both designs. Also, no significant differences in terms of gas pressure between the rings and for the rings axial lifts were observed. However, figure 5 presents the average gas flow between the rings, including the engine blow-by. This figure shows $29 \%$ of blow-by reduction for the "initial proposal" design (from $29.3 \mathrm{l} / \mathrm{min}$ for the "pre-design" to $20.7 \mathrm{l} / \mathrm{min}$ for the "initial proposal"). Based on PRIDE analysis, the "initial proposal" design minimized the blow-by without jeopardized the ring pack dynamic behavior, contributing for an initial PCU design proposal more robust and closer to the customer needs.

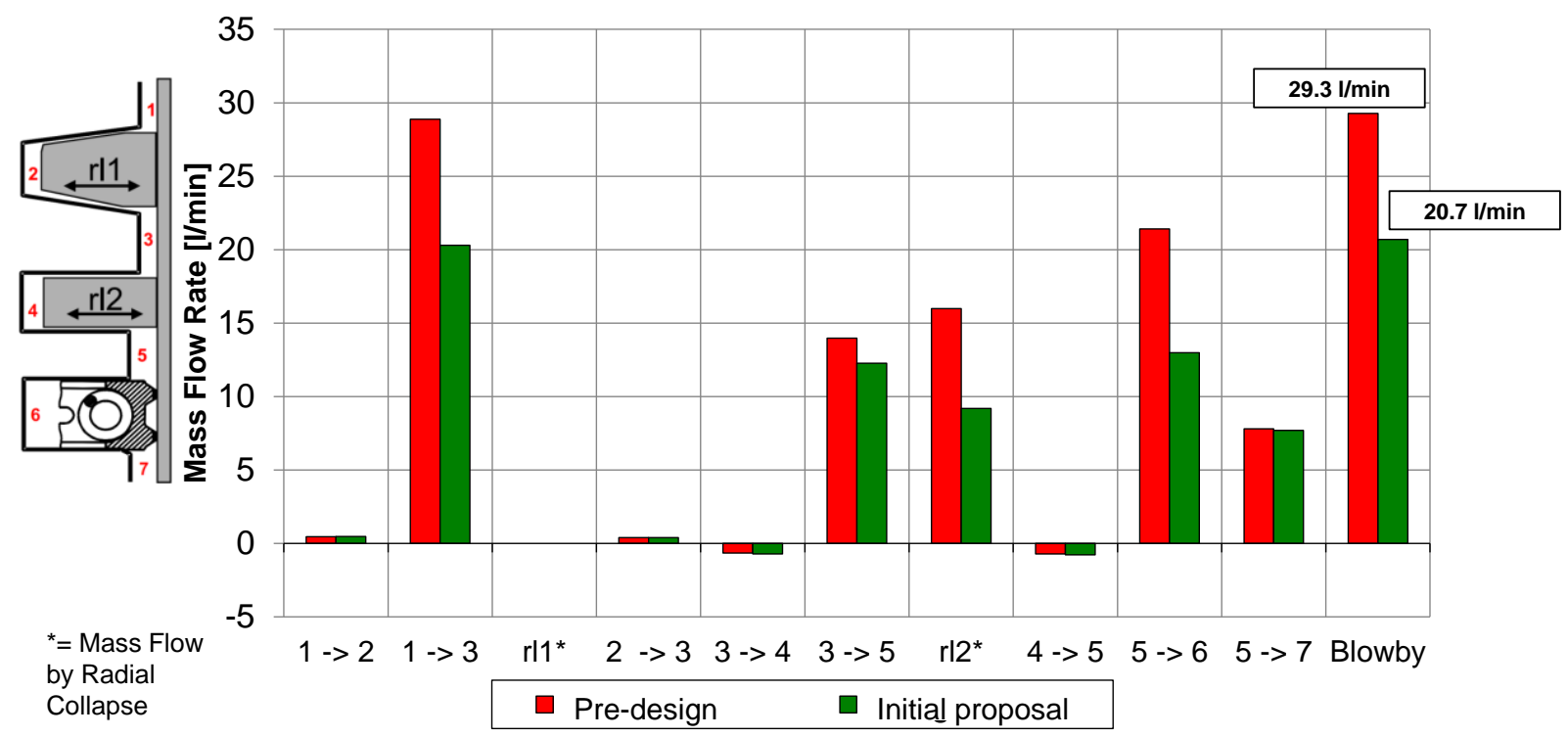

Figure 5 - Average gas flow between the rings and blow-by (case study 1) 


\subsection{Case Study 2 - Diesel engine}

The second case study presents an application of PRIDE code for a diesel engine. The target of this study was to evaluate the ring pack dynamics in order to verify the existence of any non-desirable ring behavior which could increase the oil consumption $[3,6,7,8]$. In this case study, it was adopted the same nomenclature used in case study 1 ("pre-design" and "initial proposal").

Figure 6 shows the inter-rings gas pressures and rings axial lifts. The results show an intensive top ring axial movement (ring 1) for the "pre-design" version, from 90 to 270 crank angle degrees, as a consequence of an overlap between the second and top land pressures.

This pressure overlap causes a gas reflow from second land to top land named "top groove reverse blow-by" as showed in figure 7, which may drag together lubricant oil. This is one of the most important sources of oil consumption mechanism called "blow-back". In order to eliminate this undesirable behavior, the MAHLE recommendation is to change the second ring dynamics, generating a desired intensive axial movement in the second ring by changing ring and/or piston designs.

Thus, for the "initial proposal" design, the top ring end gap was reduced, the second ring end gap was increased and the piston third land design was adjusted. With these modifications, the pressure overlap disappeared (figure 6) eliminating the "top groove reverse blow-by" (figure 7) and consequently, reducing the oil consumption tendency due to the elimination of blowback mechanism.
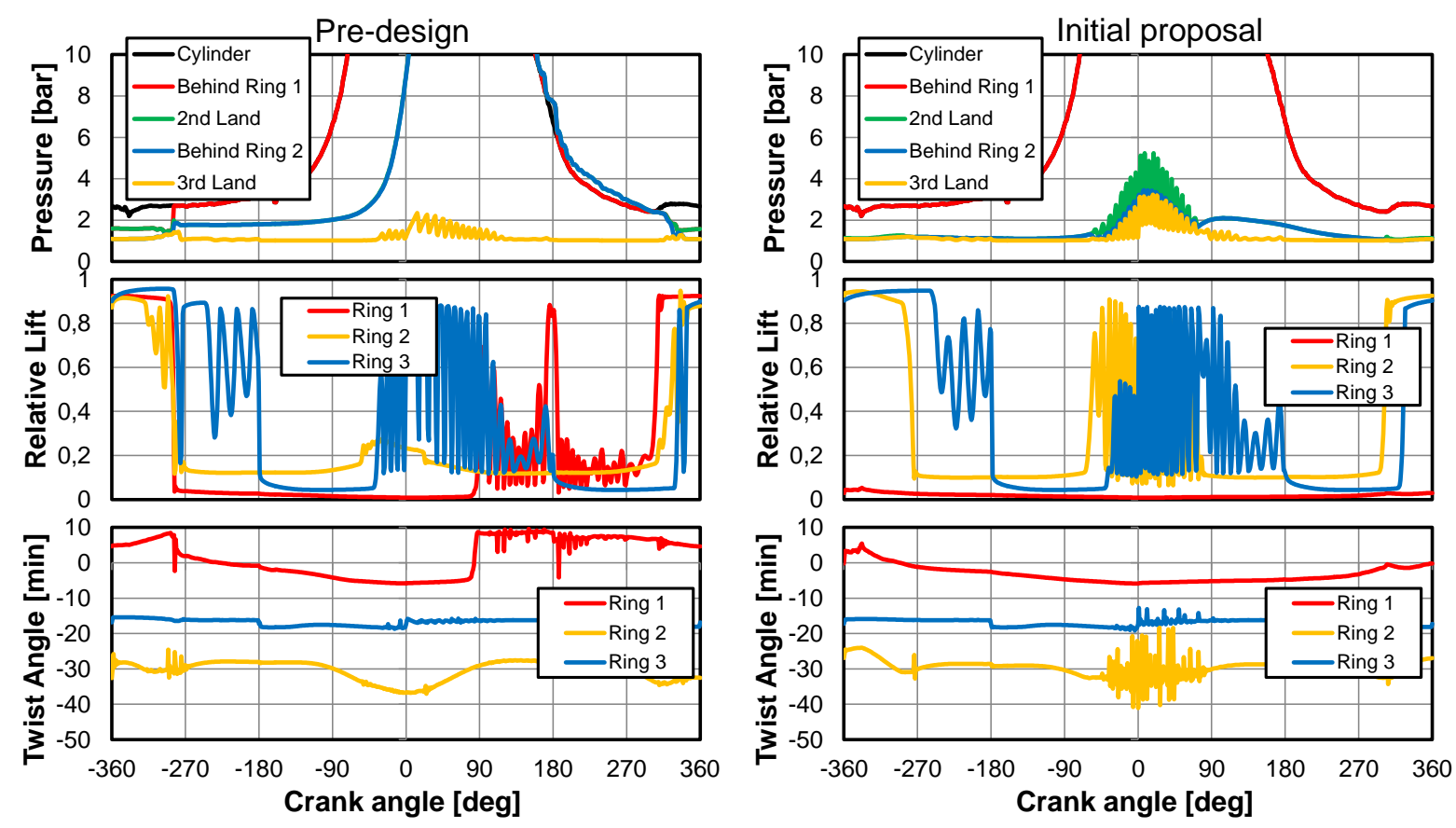

Figure 6 - Inter-ring gas pressures and rings axial lifts (case study 2) 


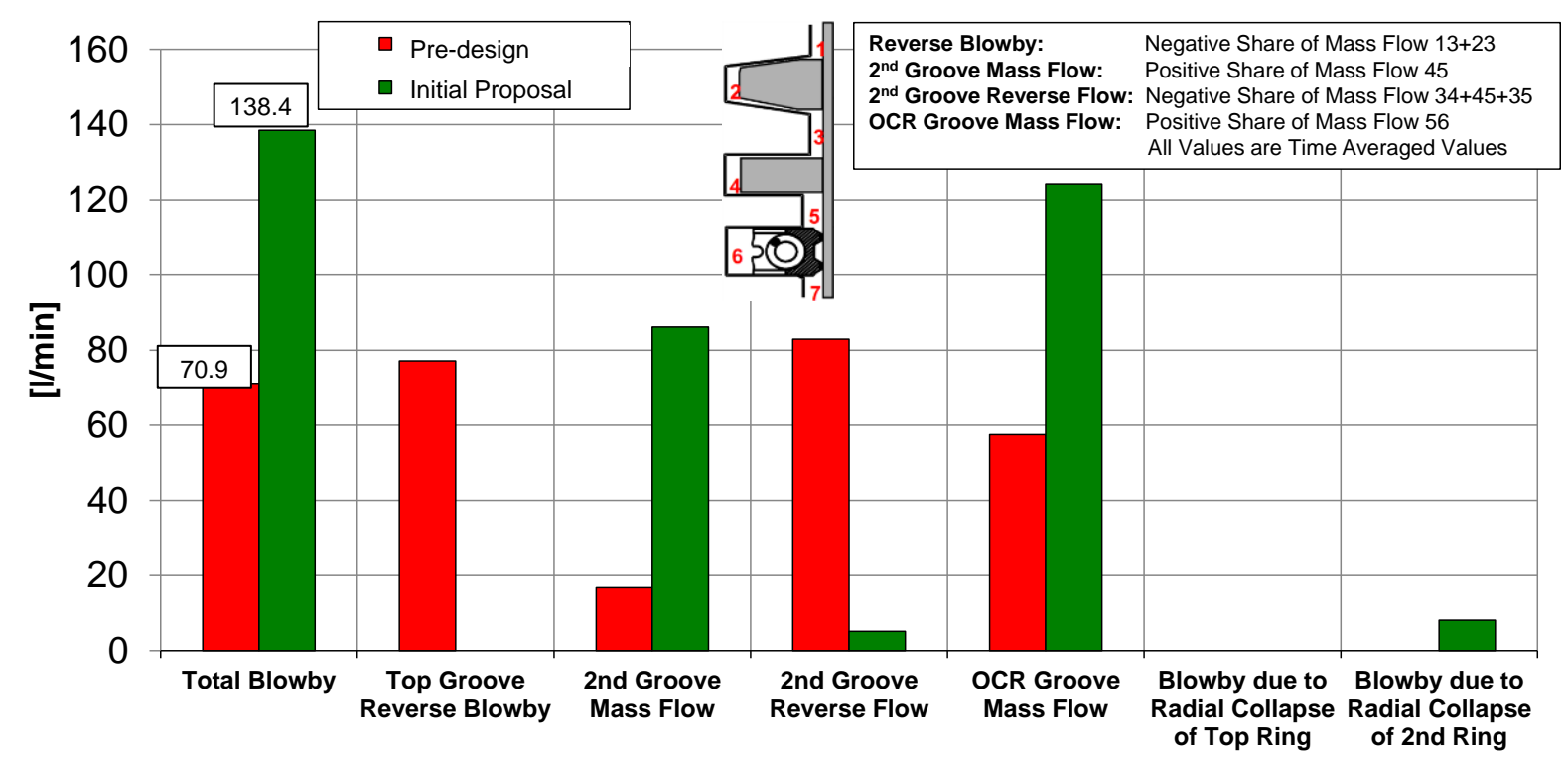

Figure 7 - Average gas flow between the rings and blow-by (case study 2)

Another advantage of the desired intensive second ring axial movement is the increase of downwards gas flow around the second ring washing the oil accumulated in this region, also minimizing the oil carbonization tendency. As expected, the blow-by increased nevertheless still remained within the customer target.

Again in this case study, the PRIDE code supported the decision for a better piston and rings initial designs.

\section{CONCLUSION}

The PRIDE code, a MAHLE global tool already implemented worldwide, was presented as one of the major steps of the ring design flow in order to improve the quality of the piston and rings initial design, minimizing the leadtime of product developments.

Two representative case studies were presented, one for SI engine and another for Diesel engine, exemplifying how PRIDE can support the initial design decision. In both cases, the use of PRIDE had enabled a design optimization before the preparation of first prototypes.

First applications of the tool already indicated at least $40 \%$ of lead-time reduction to perform a ring dynamic simulation due to its automated input data transfer from other systems as well as the automated output report. It also minimized the risk of human mistakes. Such improvements on user friendliness and speed enables a larger use at an earlier stage of product design, support customers on their tight targets for fast new engine development. 
Contact information:

Walter Zottin

MAHLE Metal Leve S.A. - Virtual Engine Development

Rodovia Anhanguera, sentido interior - capital, km 49,7 - Bairro Tijuco Preto

Jundiaí - SP - 13210-877

Tel.: (011) 4589-0820

E-Mail: walter.zottin@br.mahle.com

Marcos Manoel Valverde Pereira

MAHLE Metal Leve S.A. - Virtual Engine Development

Rodovia Anhanguera, sentido interior - capital, km 49,7 - Bairro Tijuco Preto

Jundiaí - SP - 13210-877

Tel.: (011) 4589-0650

E-Mail: marcos.pereira@br.mahle.com

\section{REFERENCES}

[1] TIAN, Tian., Modeling the Performance of Piston Ring Pack in IC Engines. USA: Ph.D.Thesis, the Department of Mechanical Engineering, MIT, June, 1997.

[2] Tian, T., Noordzij L. B., Wong, V. W. and Heywood J. B., "Modeling Piston Ring Dynamics, Blow-by and Ring Twist Effects", ASME 1996, ICE-Vol.27-2 Fall Technical Conference, 1996.

[3] Gulwadi, S. D., "Analysis of Lubrication, Friction, Blow-by and Oil Consumption in a Piston Ring Pack", presented at the ASME-ICE 1997 Spring Conference.

[4] Furuhama, S. and Hiruma, M., "Piston Ring Motion and its Influence on Engine Tribology", SAE paper 790860, 1979.

[5] Zottin, W., "Simulação da Dinâmica de Anéis de um Pistão Utilizado em Motores de Combustão Interna", Mechanical Engineering MSc Thesys, USP/POLI, São Paulo, 1993.

[6] Zottin, W., Bacchin, P. and Garcia, A., "Numerical Simulation Study of Carbon Build-up and Oil Consumption in a Heavy Duty Diesel Engine," SAE Int. J. Engines 5(3):2012, doi: 10.4271/2012-01-1326.

[7] Zottin, W., Clemente, M., and Villar C.A. "Heavy Duty Diesel Engine Lube Oil Consumption Simulation and Correlation with Engine Tests," ASME Fall ICE Meeting, 2000

[8] Tian, T., Rabute, R., Wong, V. W., and Heywood, J. B., "Effects of Piston-Ring Dynamics on Ring/Groove Wear and Oil Consumption." SAE Paper 970835.

[9] Zottin, W. and Cucco, A.P.C.,"Application of Optimization Techniques in the Design of Engine Components", SAE paper 2008-01-0219, USA, 2008.

[10] Zottin, W. and Trindade, W and Clemente, M. and Bertoncini, R.B, and Almeida, G.M. "The Application of Virtual Engine in a PSA 1.41 SI Engine", SAE paper 2010-36-153I, 2010. 